\title{
SEAFLOOR MAPPING OF THE ATLANTIC OCEAN BY GMT: VISUALIZING MID-ATLANTIC RIDGE SPREADING, SEDIMENT DISTRIBUTION AND TECTONIC DEVELOPMENT
}

\author{
DOI: https://doi.org/10.18509/AGB.2020.16 \\ UDC: $528.235: 551.242 .2(261)$ \\ $528.235: 551.35(261)$
}

Polina Lemenkova

Ocean University of China, College of Marine Geo-sciences. Qingdao, China

corresponding author: pauline.lemenkova@gmail.com

\begin{abstract}
The study presents the insights of the tectonic development and geological settings of the Atlantic Ocean supported by cartographic visualization in Generic Mapping Tools (GMT). The aim is to study geologic situation and trends in the tectonic development of the Mid-Atlantic Ridge and Atlantic Ocean seafloor. The objective is to find out impact of various factors (such as volcanic, tectonic, hydrothermal and sedimentary processes) that sculpt seafloor geomorphology, and correlation between early history of crust formation, geological processes and present submarine landforms. Other assignments in this work refer to mutual comparison of raster grids on sedimentation, topography, geology, seafloor fabric and highlighting similarities among the landforms and sediment thickness. Asymmetry in crustal accretion is explained by the tectonic history of the lithosphere formation. Correlation between plate subduction and development of the submarine landforms is explained by the Earth's crust extension resulting in formation of cracks, elongations, faults, rifts. Ocean seafloor geomorphology is shaped by a variety of factors that impact its form at different scales. These drivers (tectonic evolution, oceanic currents, hydrology, sedimentation) have effects on geomorphic landforms of the seafloor in context of historic geological development and during Quaternary. Technical part of this work was performed by GMT scripting toolset with all maps plotted in American polyconic projection. The results are received by overlay, cartographic analysis and synthesis of the multi-source geodata through mapping and interpreting grids (ETOPO1, EGM96, GlobSed, crustal age). This work contributes to expand the knowledge on geological and tectonic development of the Atlantic Ocean seabed in order to complete the view of its submarine geomorphology
\end{abstract}

Keywords: Keywords: Cartography, GMT, Geovisualization, Mapping, Geospatial Data, Atlantic Ocean, Geology.

\section{INTRODUCTION}

The study focuses on the insights of the tectonic development and geological settings of the Atlantic Ocean (Fig. 1). The most notable morphological structure of the Atlantic seafloor is its mid-ocean ridge, which stretches along the entire Atlantic Ocean. The Mid-Atlantic Ridge (further: MAR) separates two zones of deep-sea basins in the Atlantic Ocean, bordering continental blocks through the systems of troughs [28]. It begins in the Eurasian part of the Arctic Ocean from the Gakkel Ridge, stretches southwest through the NorwegianGreenland basin and then continues across the entire Atlantic Ocean about halfway between the shores of North and South America on the one hand, Europe and Africa on the other. The MAR has a well-defined rift valley, displaced by transform faults. The structure of the Atlantic Ocean is an example of a slow-spreading mid-ocean ridge and ridge-to-ridge transform faults. Its basins is geologically stable, with the exception of the hot spot areas. The importance of MAR is caused by its structural connectivity with other marine geological objects on the seafloor: MAR is a part of the global planetary geomorphological structure that forms a system that includes the seafloor of the oceans. 


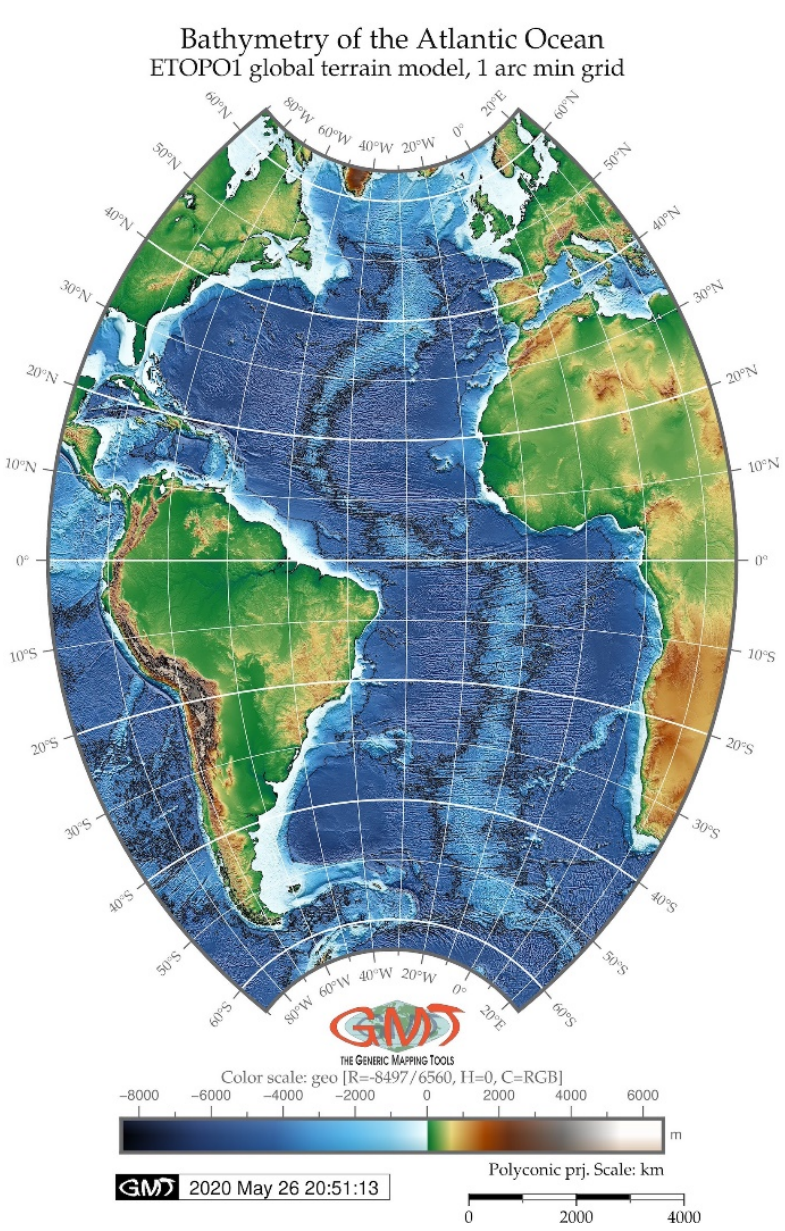

Figure 1. Topographic map. Source: author.

The importance of the Atlantic Ocean can be explained by the fact that its basin and margins became a main region for testing concept of the tectonic development. Several geological concepts, such as geosynclinal theory, continental drift and spreading was created on the basis of the observations of the geologic structure of the Atlantic Ocean which initiated the development of the new global tectonics. The MAR of the Atlantic Ocean demonstrates impact of various processes, such as volcanic, tectonic, hydrothermal and sedimentary processes sculpt geomorphology in the oceanic seafloor [27] and deep correlation between climatic and geological processes [11]. Because of the poor accessibility and remote location of the

\section{DATA AND METHODS}

For visualization and thematic mapping of the raster grids (tectonics, geology, topography, geoid), the workflow was as follows:

1. Terrain data was visualized using ETOPO1 1 arcminute global relief model of Earth's surface [1] using Generic mapping Tools (GMT) [31] and data conversion by Geospatial Data Abstraction Library

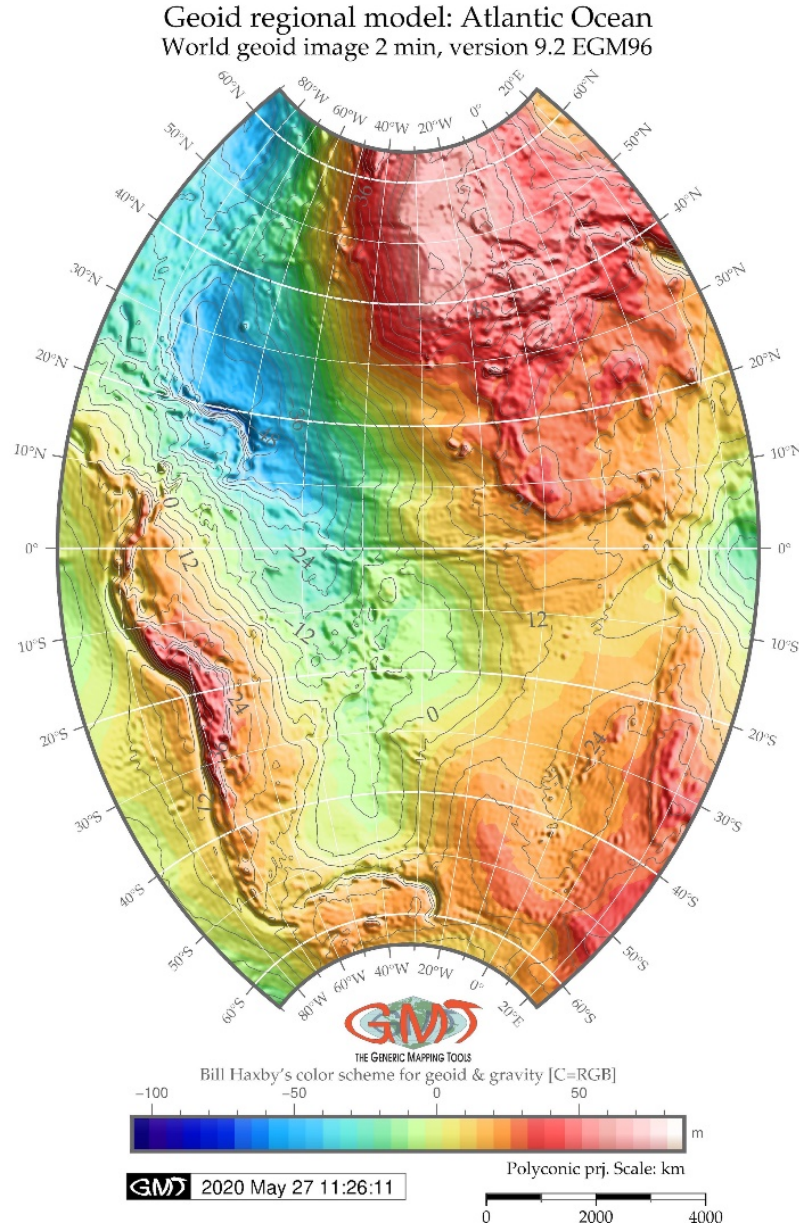

Figure 2. Geoid model. Source: author.

oceanic seafloor, using advanced cartographic technologies [4], [12-16] and automatization [25] has been important for mapping and investigation of the geomorphic features and settings of the submarine landforms. Although a primary objective of the GMT based approach demonstrated in this research is to develop advanced shell scripting mapping techniques, collate multi-source data and algorithms, it is intended that systematic approach of marine geological analysis can function independently at other GIS, e.g. ArcGIS using traditional methodology of GUI [7-10] for visualization of raster and vector data grids (geology, topography ETOPO1).

(GDAL) [49]: NetCDF to GeoTIFF. Besides ETOPO1, there are several existing data grids that can also be used for mapping, e.g. World Topographic Map [44] which provides a base map coverage for the world down to a scale of ca. 1:72k. Other useful grids include open source free GEBCO bathymetric grid (GEBCO Compilation Group 
2020) [45], commercial ESRI based World Ocean Base map which gives an Ocean Base map providing coverage for the world down to a scale of ca. 1:577k [46], National Geographic World Map by commercial ESRI is released in global coverage down to ca. 1:144k scale, SRTM raster grid [50].

2. The thematic visualization was based on using raster grids and vector layers: geoid data were derived from raster grids EGM96 [24]; total sediment thickness in the world's oceans using raster grid [26]; Age and spreading asymmetry of the world's ocean crust from [22]; tectonic seafloor fabric of the ocean basins and marine geology [21]. Other geophysical data that can be used for gravity modelling include EGM2008 and geopotential gravity grids [47], [48]. Seafloor features are defined and internationally recognized in the existing GEBCO Gazetteer [51].

3. Vector and raster grids were visualized by GMT [52] using shell scripting and available methods [17-19] to form the basis of geological complexity of the Atlantic Ocean. Visualization was done by sequential algorithms of GMT. An overlay of the thematic layers using rule-based plotting of the geospatial objects was then performed (Fig. 1-6). More specifically, the methodology of the GMT includes the following cartographic routine. To generate the seafloor age grids used to evaluate the performance of GMT algorithm, this work employed a 2 arc min netCDF grid Version 3 by NOAA processed by GMT as an input plate model with the following conditions presented below in 10 steps. The technical methodological example of plotting map in a GMT below is presented for map on Fig. 5 'Age of Oceanic Lithosphere: Atlantic Ocean'. All other maps were using the same principle with different small modifications, such as annotations, initial raster grids for geovisualization, colour palettes, legends and cartographic elements:

1. First step: the raster image was subset from the whole grid using the following command: 'grdcut age.3.2.nc -R-90/25/-65/65 -Gao_age.tif'. Here the flag '-R-90/25/-65/65' means the region with coordinates in west-east-south-north direction. The file 'ao_age.tif' was then processed in following steps.

2. The grid was then examined for its statistics by 'gdalinfo' utility of GDAL library: gdalinfo ao_age.tif -stats. The results include a range in oceanic age: Minimum $=0$, Maximum $=27891$ (corresponds to the 278,91 M years of age).

3 . The 3rd step includes generating a color palette using Google 'turbo' cpt using GMT module 'makecpt': gmt makecpt -Cturbo -T0/27891 > age.cpt.

4. The 4th step includes creating a file by code: ps $=$ AO_Age.ps and visualization of the image which was already cut off at the 1st step: 'gmt grdimage ao_age.tif -Cage.cpt -R-90/25/-65/65 JPoly/4i -P -I+a15+ne0.75 -Xc -K > \$ps'. Here, the '-Jpoly/4i' flag corresponds to the Polyconic projection which was applied for all the maps for compatibility and a '4i' means set up a mapping layout in 4 inches.

5.The 5th step include adding a grid on the map using the following code: 'gmt psbasemap -R -J Bpx20f10a20 -Bpyg20f10a10 -Bsxg10 -Bsyg 10 $\mathrm{B}+\mathrm{t}$ "Age of Oceanic Lithosphere: Atlantic Ocean" -O -K >> \$ps'. Here, the flags following '-B' correspond to the interval of grid ticks (major and minor, by latitude and longitude, annotations on $\mathrm{X}$ axis and $\mathrm{Y}$ axis, correspondingly). This stp was done using 'psbasemap' module o GMT. The flags '-O' and '- $\mathrm{K}$ ' corresponds to the commands 'overlay' and 'continue scripting', respectively.

6 . The scale with its annotation and the directional rose were added using GMT code 'gmt $\begin{array}{llll}\text { psbasemap } & -\mathrm{R} & -\mathrm{J} & -\mathrm{Lx} 7.8 \mathrm{c} /-\end{array}$ $3.7 \mathrm{c}+\mathrm{c} 50+\mathrm{w} 4000 \mathrm{k}+1$ "Polyconic prj. Scale: $\mathrm{km} "+\mathrm{f}$ $-\mathrm{UBL} / 1.0 \mathrm{c} /-3.7 \mathrm{c}-\mathrm{O}-\mathrm{K}>>$ \$ps'. Here '-L' flag gives a command for plotting projection scale bar below the map and a '-UBL' flag gives a technical time stamp of the map production. The flags'-R' and ' $-J$ ' tell the machine to plot a map using given projection (which was set up in previous step) and a region.

7. The 7th step includes adding a color scale bar below the map using the GMT module 'psscale' by the code: 'gmt psscale -R -J -Cage.cpt $\mathrm{DjBC}+\mathrm{o} 0.0 \mathrm{c} /-3.0 \mathrm{c}+\mathrm{w} 8 \mathrm{c} / 0.5 \mathrm{c}+\mathrm{h} \quad-\mathrm{Baf}+\mathrm{l}$ "Color scale: turbo (Google's Improved Rainbow Colormap for Visualization [C=RGB])" -I0.2 By+lm -O -K > \$ps'.

8. The 8th step includes adding a GMT logo and placing it below the map using 'logo' module:gmt logo -Dx3.9/-2.0+o0.1i/0.1i+w2c -O -K >> \$ps

9. The 9th step adds a subtitle under the main title of the map: 'gmt pstext -R0/10/0/15 -JX10/10 $\mathrm{X} 0.5 \mathrm{c} \quad-\mathrm{Y} 6.7 \mathrm{c} \quad-\mathrm{N} \quad-\mathrm{O} \quad-\mathrm{F}+\mathrm{f} 10 \mathrm{p}$, PalatinoRoman,black + jLB $>>$ \$ps $<<$ EOF 1.5 9.3 Age of 
the ocean crust, 2 arc min grid V-3 EOF'. Here the 'EOF' corresponds to the 'end of file' Linux expression and the text to be print goes between the 'EOF' flags.

10. The final 10th step includes converting the resulting postscript file to the image file using GhostScript: 'gmt psconvert AO_Age.ps -A1.5c E720 -Tj -Z'.

The technological scheme of scripting illustrated above was used as a principle method for plotting all the maps presented in this paper. The changes were only made for the initial data grids (topographic grid, sediment thickness, tectonic, gravity and geoid and grids). The principal method of the GMT, as illustrated above by the example of coding in 10 steps. This is a core and main difference between the GMT and traditional GIS software programs that mainly use a graphical user interface (GUI) for cartographic output and plotting.

Examples of previous works of geovisualization of the Atlantic seafloor are diverse. To mention some examples, these include both traditional GIS (ArcGIS) and specialized geological software. For instance, the 4DPlates tectonic geovisualization uses grids with a 4-8 tree structure to store the data with the required resolution, which means that the cartographer can interact with large data sets on the fly [33]. GPlates is another useful software for tectonic plate reconstruction and open-source paleogeographic system enabling visualization of the historical development of tectonic movements presented in a variety of papers, e.g. [34], [35], [36], [37].

Besides 2D maps and graphics, interesting example of the 3D modelling of the Atlantic Ocean seafloor is presented by [38] where the authors present a map-view geometry of the oceanic core complexes relates to magma supply variations and demonstrate how a 2D physics can predict 3D fault behaviour and may be used to infer magma supply. A 3D modelling of the seafloor can be made using GMT [39], [40] by module 'grdview.

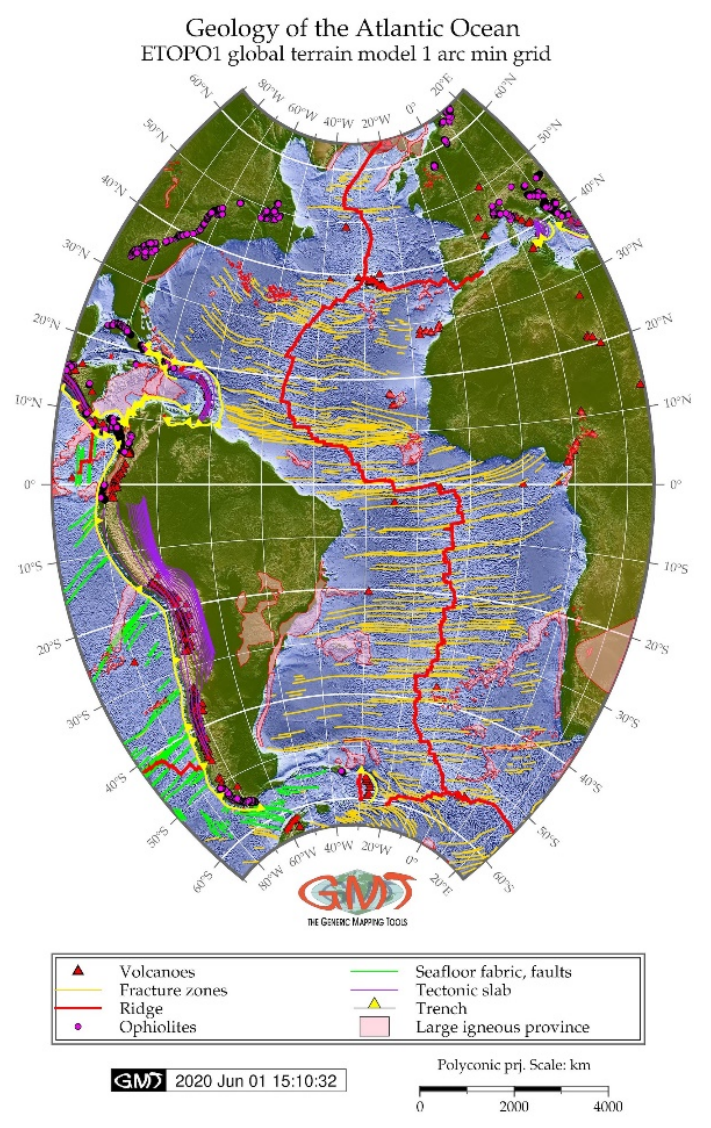

Figure 3. Geologic map. Source: author.

\section{GEOLOGY}

The axial zones of the MAR present the constructive boundaries of the lithospheric plates, where the ocean seafloor is being extended and the oceanic crust is being formed. The geomorphology 
of the MAR has very dissected shape relief form: the tops of the submarine ridges and seamounts are point-shaped with steep slopes (up to $15-20^{\circ}$ ) and concave troughs bottoms. Both flanks of the MAR are gradually decreasing on both sides of the MAR axis, with almost the same block-ridge dissection as the rift zone. The slopes of the blocks and ridges have average steepness of ca. $10^{\circ}$ and are

\section{TECTONICS}

Geologic submarine observations made in the rift zones of the MAR indicate processes of the Earth's crust extension. These include numerous cracks, elongations, faults, with the number and size of cracks increasing on both sides of the axial zone [3]. The continuity of the isochrons stretching $10 \mathrm{Ma}$ indicates that current position of the rift zones was formed during Miocene and almost did not change since then [5]. Near the Fracture Zone, and in the

\section{SEDIMENTATION}

Based on the data received by the deep-sea drilling, Cretaceous and possibly Jurassic deposits lie at the base of the seafloor [20]. Cenozoic sediments comprise a smaller part of the seafloor, and their thickness in the pre-continental trough does not exceed $2 \mathrm{~km}$ The sediments are represented by the Upper Jurassic to the Neogene-Quaternary, with the complicated by minor geomorphic dissections, such as small steps and pointed peaks [30]. The bottom between the submarine ridges is elevated and mostly flat. Towards outer borders of the ridges, the height of the blocks and ridges becomes smaller, and the bottom of the troughs is wider, which indicates the increasing role of accumulative alignment.

tropical zone of the Atlantic, the isochrons pass near the continental margins, which indicate the convergence and connection of the continents in the middle of the Cretaceous [2]. The isochrons in the northern region of Atlantic, north of the CharlieGibbs Fracture Zone, extend along the foot of the continental slope of Greenland and slope of the Rockall Plateau $\left(55-60^{\circ} \mathrm{N}\right)$ formed ca. $55 \mathrm{M}$ years ago [32].

Cenozoic sediments [29] taking smaller areas: $1 \mathrm{~km}$ on the shelf to 2-3 km in depressions. Ancient rocks are exposed on structural terraces on the steep sections of the continental slope and on the walls of the underwater canyons, bending downward in shallow topographic depressions.

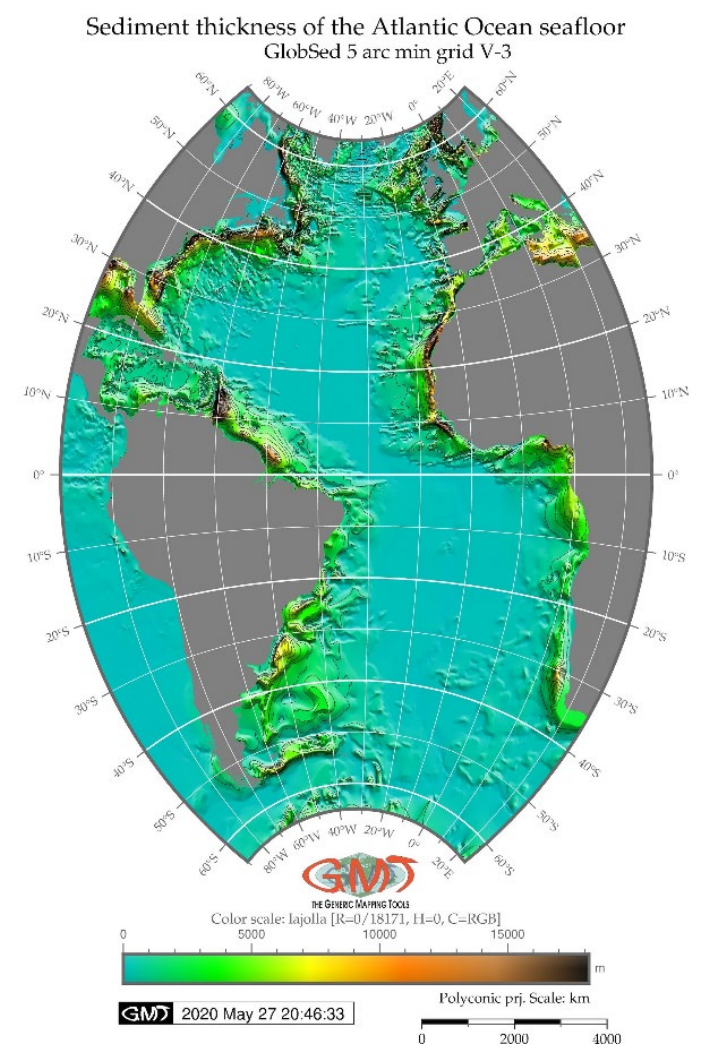

Figure 4. Sediment thickness of the Atlantic Ocean. 
South American shelf along the coasts of Guiana and Brazil is notable for the eroded surface of the basement with deposits from the Upper Jurassic to Quaternary [23]. Such sediments structure shows breaks indicating regressions and transgressions of the ocean during its historical geologic development. Coastal or lagoon deposits predominate on the basement with upper layers of shelf sediments. The total sediment thickness in the regions of $8^{\circ} \mathrm{S} 34^{\circ} \mathrm{W}$ takes $0.5 \mathrm{~km}$, southwards it increases up to $3 \mathrm{~km}$ on the Abrolhos Bank, which is characterized by an enlargement of the Brazilian shelf, further increase of sedimentation off Brazil's central coast takes up to $3.5 \mathrm{~km}$, and in the Amazon

\section{RESULTS}

The paper presents the results of the GMT based geovisualization of the series of the thematic raster maps using design and functionality of the GMT modules. The cartographic visualization os all maps is presented in American Polyconic projection, for comparative analysis and the compatibility of the overlays. Using grids of the oceanic seafloor age processed by GMT enabled to reconstruct historic development of the seafloor in the distant past based on the open rater data. The application of geological vector layers presented geologic settings
Delta (near its mouth around $0^{\circ} 50^{\prime} \mathrm{N} 50^{\circ} \mathrm{W}$ ) over 10 $\mathrm{km}$ (beige colors on the Fig. 4). Along the coast of Argentina, sediment exceeds $6 \mathrm{~km}$ in the depressions of the basement surface, while on the rest of the shelf it decreases to $1-2 \mathrm{~km}$. The basement of the Argentina coast is represented by the deposits from the Upper Jurassic to the Neogene-Quaternary [6]. Changing facies from the lagoon bottom to the shelf indicate sequential immersion of the continental margin in the MesoCenozoic. The sediment thickness takes up to 3-4 $\mathrm{km}$ in the continental depression (light emerald green colours on Fig. 4).

of the Atlantic Ocean seafloor for comparison with other thematic maps. The relief of the MAR is generally distinguished by the complex geomorphological dissection (Fig. 1). It is formed by complex variations of ridges, grabens, horsts, ledges, plateaus, seamount chains linearly elongated along the strike of the ridge. All this variety of geomorphic forms of the submarine topography of the MAR of the Atlantic Ocean can be classified into three main geomorphological zones: a rift and two flank on its both sides.

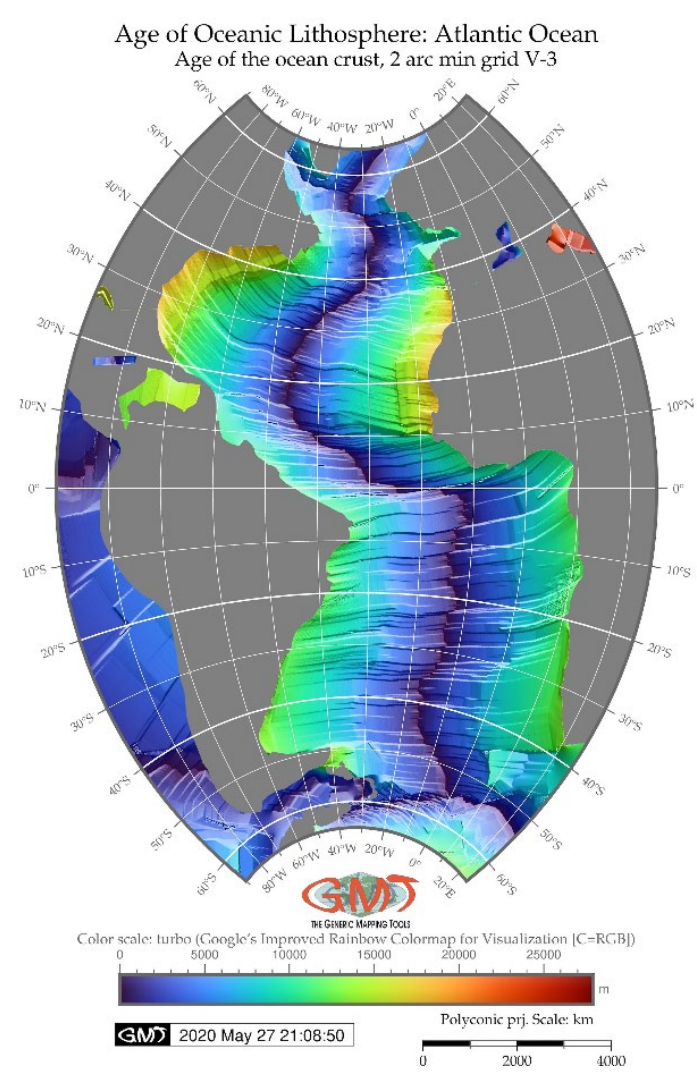

Figure 5. Age of oceanic lithosphere. Source: author. 
The MAR is characterized by specific features of the structure in its submarine relief, abnormal geophysical fields, tectonic movements, seismicity, volcanism, reflected in variations in the gravitational potential model of geoid (Fig. 2) The ridge zone of the MAR (red thick line on Fig. 3) is intensely dissected and elevated at 1000-1500 m above its both flanks. A series of the narrow deep rift valleys and graben-like structures (yellow horizontally-directed lines on Fig. 3) formed along the axis of the MAR as a result of the extension of the stretching crust. A series of rift ridges consisting of asymmetric blocks, sometimes replaced by strongly dissected plateaus, individual seamounts or volcanic islands is placed on the both sides of the rift valley (axial ridge of MAR). The sedimentary cover of the continental margins in the Atlantic Ocean correlates with the submarine relief of its basement surface (Fig. 4). This also corresponds to the previous studies showing sediment thickness on the shelf of Labrador and Newfoundland at the outer edge of the shelf to be ca. $3 \mathrm{~km}$, increasing in local depressions and in the continental trough up to 7-8 km [2]. Norther American shelf stretching from Nova Scotia to Florida shows total sediment thickness varying from 2-6 km (bright green colors, Fig. 4) depending on local relief, and reaching 6-9 $\mathrm{km}$ in the local depressions. Visualized tectonic geophysical and gravimetric settings of the Atlantic Ocean was made using mapped variation of the crustal accretion on conjugate ridge flanks in the Atlantic Ocean in context of the lithospheric plate age. Second, the geologic settings of the Atlantic Ocean were visualized showing lineaments of the seafloor fabric, distribution and direction of the faults, ridges and fracture zones formed in context of the historical development of the geology of the Atlantic Ocean.

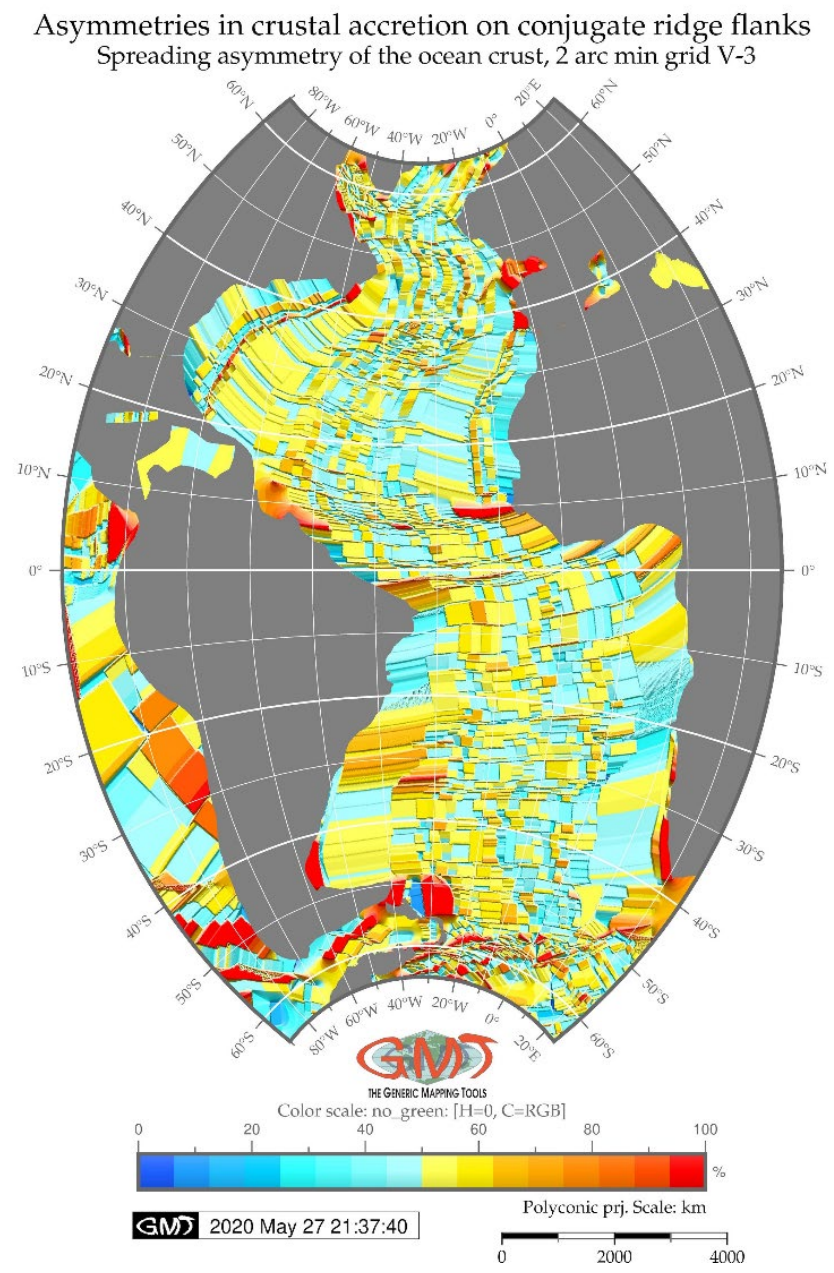

Figure 6. Asymmetries in crustal accretion. Source: author.

Examining of the Atlantic Ocean regional differences in geoid undulations shows higher values in the north-eastern part of the region
(Europe) and African part. The visualization of the topographic grid highlights the differences between the elevation and seafloor bathymetry making 
visible geomorphological structure of the submarine relief in the comparison of the topographic grids. The volcanic areas and ophiolites of the Atlantic Ocean are visualized with their closeness to the large igneous provinces (South America, Africa, the Caribbean region and certain areas of the Atlantic seafloor). Sediment density is demonstrated in contest with the topographic grid highlighting its closeness to the coastal areas and river mouth discharge zones.

Ocean lithosphere age of 60-63 M years can be seen throughout the Atlantic Ocean (Fig. 5). Isochrons correlate with the continental margins, indicating that margins were closed and there were no basins at an earlier time of the Earth history. The asymmetry in crustal accretion on conjugate ridge flanks of the Atlantic Ocean (Fig. 6) can be explained by the concept of the tectonic history of the oceanic lithosphere formation. Thus, the seafloor of the oceans as well as the oceanic crust is formed in the rift zones as a result of the rise and differentiation of the asthenospheric materials and its extension to the both sides of the axial fault. MAR presents the zone of active formation of a new oceanic crust with asymmetry caused by the variations in the spreading rates of the oceanic crust. As can be analyzed on Fig. 6: red areas are represented by the most asymmetric crustal accretion (80-100\%), blue colors ( $0-25 \%)$ as almost synchronous, azure blue $(25-50 \%)$ as partially synchronous and the most of the area covered by asynchronous areas $(50-60 \%)$. As a result of the

\section{DISCUSSION}

Comparing the obtained geovisualization results with previous results on mapping geology of the Atlantic Ocean, following remarks can be drawn. There have been significant efforts to study geological settings of the Atlantic Ocean settings in order to assess how mineral resources can be distributed depending on the topographic and geological conditions. For example, [56], [57] and [58] developed seafloor studies of the Atlantic Ocean in context of the geological resources and tectonic settings: survey of seafloor subsidence over the entire Atlantic Ocean, detecting neovolcanic zones of mid-ocean ridges which are host to seawater-derived hydrothermal systems and studies of the hydrothermal system on an active detachment fault. Other researches [59] developed asynchronous movements, parts of the oceanic seafloor with the continents form tectonic plates that move along the surface of the asthenosphere. As a result of these complex processes, a new continental crust forms in the Wadati-ZavaritskyBenioff zone, where the oceanic crust subducts under the adjacent continents.

The rock deformations in transform fault zone of the MAR are consistent with the concept of plate tectonics. The analysis of the age of horizontal movements in oceanic lithosphere which resulted in the formation of its modern morphostructure is summarized on the schematic map (Fig. 5) compiled by GMT. The map shows the age of the lithospheric plates according to the plates moving apart over a certain period of time in millions of years.

The isochrons of $10 \mathrm{Ma}$ (dark blue color, Fig. 5) correlate with the distribution of the modern rift zones extending almost continuously in the entire Atlantic Ocean along the MAR and dividing near the Bouvet Triple Junction into two branches with opposite directions. The youngest areas correspond to the red color $(250 \mathrm{M}$, area of modern Mediterranean Sea) and yellow colors near the west African and North American coasts (age of 150 180 M, Fig. 5). The basin of the Atlantic Ocean has variations in lithosphere age of 50-150 M (Fig. 5). The age of the oceanic lithosphere by isochronous of $80 \mathrm{M}$ (Fig. 5) are observed in the Atlantic Ocean only south of the Charlie-Gibbs Fracture Zone $\left(52,50^{\circ} \mathrm{N}\right)$.

a studies in selected segment of the Mid-ocean Ridge to measure the metal fluxes and resource potential. Some papers presented studies of the geovisualization of the ISC geological data [60], geological mapping and assessment of the bathymetric variations [61], studies of the variations in the geomorphology depending on the specific location of the dee-sea trench within the selected study area [62]. Other papers presented studies of the anomalous water temperatures over the Mid-Atlantic Ridge across a crest at $26^{\circ} \mathrm{N}$ [63] which are comparable with studies presented by [64] and [65].

Mapping spatial distribution of the geological faults, tectonic slabs, fracture zones, volcanoes, using methods of GMT provided some key findings 
regarding the geological settings of the Atlantic Ocean seafloor through geovisualization. The first relates to the complex analysis of the datasets for making comparative analysis of the various layers, such as sediment thickness, tectonics, seafloor tectonic development and topographic features. The method of using GMT scripting for overlay of various maps is faster in comparison to the traditional GUI based GIS because applying scripts for different datasets for the entire research area was carried out using scripting templates with adjustments of color palettes, input data and annotations, whereas GIS methods require generating large GIS projects.

Another characteristic investigated was the spatial independence of the presented method of GMT. It was determined that the GMT scripting, in contrast to the GIS methods, is a spatially independent due to the flexibility of the projection adjustment. In contrast, if the projection is changed in a GIS project, all layers will be applied to the new projection, while GMT can operate with any map independently. Furthermore, data capture from the available open sources presents free high resolution datasets in NetCDF format that are compatible with GMT (GMT can read NetCDF format) which enables to perform quality mapping layouts. In contrast, the use of some other GIS is limited to their specific formats.

Hence, it turned out that the greatest difficulties arise in the syntax of the GMT that require learning the language and mastering the programming code

\section{CONCLUSION}

The purpose of this study was to demonstrate the application of the cartographic scripting toolset GMT for processing high resolution datasets of the Atlantic Ocean seafloor. Using advanced cartographic technical solutions, such as GMT, enables to obtain new maps using multi-source data (geology, topography, tectonics, geoid) through geovisualization. Printing quality maps based on high resolution grids enables to highlight correlation between the geological phenomena with topographic setting which reflects the tectonic evolution of the seafloor. This helps to yielding better knowledge and understanding of the geological processes that take place on the oceanic seabed. Precise and correct geovisualization contributes to better geological analysis, prognosis principles together with console based operating with layers. In addition to the increased difficulties of the GMT syntax, the problem also lies in the possible computer memory. For instance, the whole dataset of GEBCO has $11,72 \mathrm{~Gb}$, the SRTM grid covering the whole planet is $14,93 \mathrm{~Gb}$, the ETOPO1 grid is $933,5 \mathrm{Mb}$. These technical characteristics require capture data at the best available machines using high technical characteristics (e.g. MacBook Pro). However, as mentioned before, the GMT enables to subset necessary region form the whole dataset and continue working only with 'cut off' selected study area.

The greatest weakness of the traditional GIS is certainly its labour work and some available bags in a process of mapping. In order to perform cartographic visualization from the available grids, a GIS project with pre-defined characteristics is usually made, while GMT enables to do many adjustment 'on the fly' for each map. Other problem of traditional GIS consists in partially manual process of the digitizing of vector layers, while GMT enables effective machine-based precise geovisualization. The printing quality of the GMT based maps enables to visually evaluate cartographic elements on a layout for better and more profound interpretation (lines, contrasting or sequential color palettes, polygons, overlay of layers (following one after another in a script) which enables each individual element on a map to be recognized clearly.

and predicting of the mineral resources distribution. Comparison of the presented maps base don the GMT scripting methods with the already existing maps of the Atlantic Ocean made using other GIS and methods showed that both GIS and GMT present efficient mapping. However, the GMT based method differs significantly in its principal characteristics: a scripting approach. The possibility of using scripts introduces the machine learning methods in cartography and mapping. That means that using a script increases two main characteristics of the cartographic routine: 1) a speed of mapping; 2) a precision of mapping. Indeed, a repeatability of the cartographic script results in faster plotted maps and reduced number of human-caused errors, misprints, mistakes and 
drawbacks that are usual in the process of handmade digitizing and plotting using GUI. Instead, the machine made plotting proved to be more accurate, objective, and aesthetic comparing to the proprietary GIS made maps. Moreover, in contrast to the GIS made geovisualization methods, a GMT can process independent datasets and grids without need to generate a project. That means, the maps presented in this research were plotted independently and can be reprinted in the future with any changed technical characteristics on the fly: modified projections, colors, using other raster grids for the same script, overlaying layers and their transparency, etc.

As for datasets quality, resolution and size, if the precision of the mapped geological and topographic layers is not sufficient or the study area only encompasses the selected certain smll area, using GMT is also advantageous for the following reason: it enables to cut off only a small peace of the whole datasets through the 'grdcut' module and then to visualize the subsetted grid by 'grdimage' module. Thus, it significantly reduces the computer memory, which is especially useful for processing very large (in terms of file size) or high-resolution datasets, such as GEBCO or SRTM.

In general, the choice of the cartographic methodology mostly depends on several factors. These include (1) first, the purpose of mapping; (2) second, the scale of the study area (local, regional, global); (3) third, the geological settings and topographic conditions (e.g., highly hilled terrain, high seismicity, repetitive volcanism, sediment thickness and closeness of the rivers discharging the sediment); (4) available datasets, raster grids and vectors layers, and other resources (tables, scanned maps, descriptions). A GMT approach consisting in modules splits the whole task into several sub-tasks which results in simplified techniques that enables to deal with such tasks and process any data depending on scale and data quality. Finally, selecting and changing color palettes by GMT enable to highlight or, on the contrary, to make more transparent some layers which can help to focus on some visualized phenomena.

In contrast, a GIS made approach requires creating a project which is a consequence of the higher labour of the cartographer and time consuming in terms of work. Finally, in terms of repeatability, a GMT method is based on the open source free toolset GMT, while some known GIS (e.g. ArcGIS, Erdas Imagine) are commercial licensed software. Needless to say that using an open source toolset is more appropriate from a user perspective because is it much easier to access and use. In principle, the approach of the systematic thematic mapping for geological analysis is applicable regardless of the GIS that is used. However, given the briefly discussed advantages of the GMT, it is recommended for usage by cartographers and geologists.

To conclude, the paper demonstrated an integrated approach for mapping multi-source data of the Atlantic Ocean seafloor with a special focus on MAR, through combination of the raster and vector data on tectonics, geology, lithosphere, topography, gravitation fields, seafloor fabric. Highly detailed bathymetric grid (ETOPO1) in correlation with seafloor geological lineaments and tectonic data was used to identify complex geological structures of the Atlantic Ocean seafloor and highlight correlations between the topographic, geophysical and geological phenomena.

\section{ACKNOWLEDGEMENT}

Funding: CSC SOA, Marine Scholarship of China, Grant 2016 SOA002.

\section{REFERENCES:}

[1] Amante C. \& Eakins B.W. ETOPO1 Global Relief Model converted to PanMap layer format. NOAA-National Geophysical Data Center, PANGAEA, 2009.

[2] Ballard R.D. \& Van Andel T.H. Morphology and tectonics of the inner rift valley at lat. $36^{\circ} 50^{\prime} \mathrm{N}$ on the MidAtlantic Ridge. Geological Society of America Bulletin, vol. 88(4), pp. 507-530, 1977.

[3] Frol V.V. Geomorphology of the rift zone in the Middle Atlantic Ridge. Moscow, Nauka, pp 95, 1987.

[4] Gauger S., Kuhn G., Gohl K., Feigl T., Lemenkova P. \& Hillenbrand C. Swath-bathymetric mapping. Reports on Polar and Marine Research, vol. 557, pp. 38-45, 2007.

[5] Hain V.E. The origin and age of the continents and oceans. New data on the structure of the Earth and Earth's crust. 
Moscow, Znanie, 1960.

[6] Ilyin A.V. Geomorphology of the bottom of the Atlantic Ocean. Moscow, Nauka, pp 232, 1976.

[7] Klaučo M., Gregorová B., Stankov U., Marković V. \& Lemenkova P. Determination of ecological significance based on geostatistical assessment: a case study from the Slovak Natura 2000 protected area. Central European Journal of Geosciences, vol. 5(1), pp. 28-42, 2013.

[8] Klaučo M., Gregorová B., Stankov U., Marković V. \& Lemenkova P. Interpretation of Landscape Values, Typology and Quality Using Methods of Spatial Metrics for Ecological Planning. 54th International Conference Environmental \& Climate Technologies. Riga, Latvia, 2013.

[9] Klaučo M., Gregorová B., Stankov U., Marković V. \& Lemenkova P. Landscape metrics as indicator for ecological significance: assessment of Sitno Natura 2000 sites, Slovakia, Ecology and Environmental Protection. Proceedings of the International Conference Minsk, Belarus, pp. 85-90, 2014.

[10] Klaučo M., Gregorová B., Stankov U., Marković V. \& Lemenkova P. Land planning as a support for sustainable development based on tourism: A case study of Slovak Rural Region. Environmental Engineering and Management Journal, vol. 2(16), pp. 449-458, 2017.

[11] Kuhn G., Hass C., Kober M., Petitat M., Feigl T., Hillenbrand C.D., Kruger S., Forwick M., Gauger S. \& Lemenkova P. The response of quaternary climatic cycles in the South-East Pacific: development of the opal belt and dynamics behavior of the West Antarctic ice sheet. Expeditionsprogramm Nr. 75 ANT XXIII/4, 2006.

[12] Lemenkova P. GMT Based Comparative Geomorphological Analysis of the Vityaz and Vanuatu Trenches, Fiji Basin. Geodetski List, vol. 74(97), no. 1, pp 19-39, 2020.

[13] Lemenkova P. Statistical Analysis of the Mariana Trench Geomorphology Using R Programming Language. Geodesy and Cartography, vol. 45(2), pp. 57-84, 2019.

[14] Lemenkova P. Topographic surface modelling using raster grid datasets by GMT: example of the Kuril-Kamchatka Trench, Pacific Ocean. Reports on Geodesy and Geoinformatics, vol. 108, pp. 9-22, 2019.

[15] Lemenkova P. GMT Based Comparative Analysis and Geomorphological Mapping of the Kermadec and Tonga Trenches, Southwest Pacific Ocean. Geographia Technica, vol. 14(2), pp. 39-48, 2019.

[16] Lemenkova P. AWK and GNU Octave Programming Languages Integrated with Generic Mapping Tools for Geomorphological Analysis. GeoScience Engineering, vol. 65(4), pp. 1-22, 2019.

[17] Lemenkova P. Geomorphological modelling and mapping of the Peru-Chile Trench by GMT. Polish Cartographical Review, vol. 51(4), pp. 181-194, 2019.

[18] Lemenkova P. Automatic Data Processing for Visualising Yap and Palau Trenches by Generic Mapping Tools. Cartographic Letters, vol. 27(2), pp. 72-89, 2019.

[19] Lemenkova P. Geophysical Modelling of the Middle America Trench using GMT. Annals of Valahia University of Targoviste. Geographical Series, vol. 19(2), pp. 73-94, 2019.

[20] Litvin V.M. Morphostructure of the bottom of the Atlantic Ocean and its development in the Mesozoic and Cenozoic. Moscow, Nauka, pp 126, 1980.

[21] Matthews K.J., Müller R.D., Wessel P. \& Whittaker J.M. The tectonic fabric of the ocean basins, Journal of Geophysical Research, vol. 116(B12), 2011.

[22] Müller R.D., Sdrolias M., Gaina C. \& Roest, W.R. Age, spreading rates, and spreading asymmetry of the world's ocean crust. Geochemistry, Geophysics, Geosystems, vol. 9(4), Q04006, 2008.

[23] Pogrebitsky Y.E., Goryachev Y.V., Osipov V.A. \& Trukhalev A.I. Structure of the oceanic lithosphere according to the results of studies on the Angola-Brazil geotraverse. Soviet geology, vol. 12, pp. 8-22, 1990.

[24] Sandwell D.T., Müller R.D., Smith W.H.F., Garcia E. \& Francis R. New global marine gravity model from CryoSat2 and Jason-1 reveals buried tectonic structure. Science, vol. 346(6205), pp. 65-67, 2014.

[25] Schenke H.W. \& Lemenkova P. Zur Frage der Meeresboden-Kartographie: Die Nutzung von AutoTrace Digitizer für die Vektorisierung der Bathymetrischen Daten in der Petschora-See. Hydrographische Nachrichten, vol. 81, pp. 16-21, 2008.

[26] Straume E.O., Gaina C., Medvedev S., Hochmuth K., Gohl K., Whittaker J.M., Abdul Fattah, R., Doornenbal, J.C. \& Hopper, J.R. GlobSed: Updated total sediment thickness in the world's oceans. Geochemistry, Geophysics, Geosystems, vol. 20, pp. 1756-1772, 2019.

[27] Suetova, I.A., Ushakova, L.A. \& Lemenkova, P. Geoinformation mapping of the Barents and Pechora Seas. 


\section{Polina Lemenkova \\ Seafloor mapping of the Atlantic Ocean by GMT: visualizing...}

Geography and Natural Resources, vol. 4, pp. 138-142, 2005.

[28] Udintsev G.B. Relief and bottom structure of the oceans. Nedra, pp 239, 1987.

[29] Udintsev G.B. Ocean floor geomorphology and tectonics. Bulletin of the Academy of Sciences, vol. 9, pp. 98-103, 1966.

[30] Udintsev G.B. \& Agapova G.V. Faults of the equatorial segment of the Mid-Atlantic Range. DAN USSR, vol. 317(5), pp. 1192-1196, 1991.

[31] Wessel P., Smith W.H.F., Scharroo R., Luis J.F. \& Wobbe F. Generic mapping tools: improved version released. Eos Trans. AGU, vol. 94(45), pp. 409-410, 2013.

[32] Zonenshayn L.P., Savostin L.A. \& Sedov A.P. Global paleogeodynamic reconstructions for the last 160 million years. Geotectonics, vol. 3, pp. 3-16, 1984.

[33] Clark, S.R., Skogseid, J., Stensby, V., Smethurst, M.A., Tarrou, C., Bruaset, A.M., Thurmond, A.K., 2012. 4DPlates: On the fly visualization of multilayer geoscientific datasets in a plate tectonic environment. Computers \& Geosciences, vol. 45, pp. 46-51. DOI: 10.1016/j.cageo.2012.03.015

[34] Boyden, J.A., Müller, R.D., Gurnis, M., Torsvik, T.H., Clark, J.A., Turner, M., Ivey-Law, H., Watson, R.J., Cannon, J.S., 2011. Next-generation plate-tectonic reconstructions using Gplates. Geoinformatics: Cyberinfrastructure for the Solid Earth Sciences. Cambridge University Press, Cambridge, pp. 95-113.

[35] Montes, C., Rodriguez-Corcho, A. F., Bayona, G., Hoyos, N., Zapata, S., Cardona, A. GPlates dataset for the tectonic reconstruction of the Northern Andes-Caribbean Margin. Data in brief, vol. 25 (2019) 104398. DOI: 10.1016/j.dib.2019.104398

[36] Peace, A. L., Welford, J. K., Ball, P. J., Nirrengarten, M. 2019. Deformable plate tectonic models of the southern North Atlantic. Journal of Geodynamics, vol. 128, pp. 11-37. DOI: 10.1016/j.jog.2019.05.005

[37] Gurnis, M., Turner, M, Zahirovic, S., DiCaprio, L., Spasojevic, S., Muller, R.D., Boyden, J., Seton, M., Manea, V.C., Boer, D.J. 2012. Plate tectonic reconstructions with continuously closing plates. Computers \& Geosciences, vol. 38, pp. 35-42. DOI: 10.1016/j.cageo.2011.04.014

[38] Howell, S.M., Olive, J.-A., Ito, G., Behn, M.D., Escartín, J., Kaus, B. 2019. Seafloor expression of oceanic detachment faulting reflects gradients in mid-ocean ridge magma supply. Earth and Planetary Science Letters, vol. 516, pp. 176-189. DOI: 10.1016/j.epsl.2019.04.001

[39] Lemenkova, P. 2020. Variations in the bathymetry and bottom morphology of the Izu-Bonin Trench modelled by GMT. Bulletin of Geography. Physical Geography Series, vol. 18(1), pp. 41-60. DOI: 10.2478/bgeo-2020-0004

[40] Lemenkova, P. 2020. Cartographic Interpretation of the Seafloor Geomorphology Using GMT: a Case Study of the Manila Trench, South China Sea. Aksaray University Journal of Science and Engineering, vol. 4(1), pp. 1-18. DOI: $10.29002 /$ asujse. 604761

[41] Ercilla, G., Vilas, F. 2008. Geological characterization of the Galicia Bank Region (Atlantic Ocean, NW Iberia): The marine geology community's response to the Prestige disaster. Marine Geology, vol. 249(1-2), pp. 1-6. DOI: 10.1016/j.margeo.2007.09.008

[42] Klischies, M., Petersen, S., Devey, C.W. 2019. Geological mapping of the Menez Gwen segment at $37^{\circ} 50^{\prime} \mathrm{N}$ on the Mid-Atlantic Ridge: Implications for accretion mechanisms and associated hydrothermal activity at slow-spreading mid-ocean ridges. Marine Geology, vol. 412, pp. 107-122. DOI: 10.1016/j.margeo.2019.03.012

[43] Sanchez-Guillamón, O., Vázquez, J.T., Palomino, D., Medialdea, T., Fernández-Salas, L.M., León, R., Somoza, L. 2018. Morphology and shallow structure of seafloor mounds in the Canary Basin (Eastern Central Atlantic Ocean). Geomorphology, vol. 313, pp. 27-47. DOI: 10.1016/j.geomorph.2018.04.007

[44] World Topographic Map. 2020. Sources: Esri, DeLorme, HERE, TomTom, Intermap, increment P Corp., GEBCO, USGS, FAO, NPS, NRCAN, GeoBase, IGN, Kadaster NL, Ordnance Survey, Esri Japan, METI, Esri China (Hong Kong), swisstopo, MapmyIndia, and the GIS User Community

[45] GEBCO Compilation Group 2020. GEBCO 2020 Grid. DOI: 10.5285/a29c5465-b138-234d- e053-6c86abc040b9

[46] ESRI World Ocean Basemap. 2020.

https://www.arcgis.com/home/item.html?id=1e126e7520f9466c9ca28b8f28b5e500

[47] Pavlis, N. K., Holmes, S. A., Kenyon, S. C., Factor, J. K. 2012. The development and evaluation of the Earth Gravitational Model 2008 (EGM2008). Journal of Geophysical Research, vol. 117, B04406.

DOI:10.1029/2011JB008916 
[48] Lemoine F.G., Kenyon S.C., Factor J.K., Trimmer R.G., Pavlis N.K., Chinn D.S., Cox C.M., Klosko S.M., Luthcke S.B., Torrence M.H., Wang Y.M., Williamson R.G., Pavlis E.C., Rapp R.H., Olson T.R. 1998. NASA/TP-1998206861: The Development of the Joint NASA GSFC and NIMA Geopotential Model EGM96, NASA Goddard Space Flight Center, Greenbelt, Maryland, 20771 USA.

[49] GDAL/OGR contributors (2020): GDAL/OGR Geospatial Data Abstraction software Library. Open Source Geospatial Foundation. https://gdal.org

[50] Werner, M. 2001. Shuttle Radar Topography Mission (SRTM): Mission overview, Frequenz, 55(3-4), 75-79. DOI:10.1515/FREQ.2001.55.3-4.75.

[51] IHO-IOC, 2012. GEBCO Gazetteer of Undersea Feature Names, October 2012 version.

[52] Wessel, P., Smith, W.H.F. 1998. New, improved version of the generic mapping tools released, Eos Trans. AGU, vol. 79(47), pp. 579, doi:10.1029/98EO00426.

[53] Hemming, S.R. 2019. New K/Ar age values and context from published clay mineralogy and Sr and Nd isotopes as tracers of terrigenous Atlantic Ocean sediments. Marine Geology, vol. 411, pp. 36-50. DOI: 10.1016/j.margeo.2019.01.007

[54] Benson, N. U., Fred-Ahmadu, O. H. 2020. Occurrence and distribution of microplastics-sorbed phthalic acid esters (PAEs) in coastal psammitic sediments of tropical Atlantic Ocean, Gulf of Guinea. Science of The Total Environment, vol. 730, pp. 139013. DOI: 10.1016/j.scitotenv.2020.139013

[55] Azaroff, A., Urriza, M.G., Gassie, C., Monperrus, M., Guyoneaud, R. 2020. Marine mercury-methylating microbial communities from coastal to Capbreton Canyon sediments (North Atlantic Ocean). Environmental Pollution, vol. 262, pp. 114333. DOI: 10.1016/j.envpol.2020.114333

[56] Calcagno, P., Cazenave, A. 1994. Subsidence of the seafloor in the Atlantic and Pacific Oceans: Regional and largescale variations. Earth and Planetary Science Letters 126(4), 473-492. DOI: 10.1016/0012-821X(94)90125-2

[57] Toffolo, L., Nimis, P., Tret'yakov, G. A., Melekestseva, I. Y., Beltenev, V. E. 2020. Seafloor massive sulfides from mid-ocean ridges: Exploring the causes of their geochemical variability with multivariate analysis. Earth-Science Reviews 201, 102958. DOI: 10.1016/j.earscirev.2019.102958

[58] Humphris, S.E., Tivey, M.K., Tivey, M.A., 2015. The Trans-Atlantic Geotraverse hydrothermal field: A hydrothermal system on an active detachment fault. Deep Sea Research Part II 121, 8-16. DOI: 10.1016/j.dsr2.2015.02.015

[59] Petersen S., Shipboard Scientific party, 2016. Metal fluxes and Resource Potential at the Slow-spreading TAG Midocean Ridge Segment (26N, MAR) - Blue Mining@Sea-RV Meteor Fahrtbericht M127. Berichte aus dem GEOMAR Helmholtz-Zentrum für Ozeanforschung Kiel, Nr. 32.

[60] Lemenkova, P. (2020). Visualization of the geophysical settings in the Philippine Sea margins by means of GMT and ISC data. Central European Journal of Geography and Sustainable Development, 2(1), 5-15. DOI: 10.6084/m9.figshare. 12044799

[61] Lemenkova, P. (2020), GMT-based geological mapping and assessment of the bathymetric variations of the KurilKamchatka Trench, Pacific Ocean. Natural and Engineering Sciences, 5(1), 1-17. DOI: 10.28978/nesciences.691708

[62] Lemenkova, P. (2019). Geospatial Analysis by Python and R: Geomorphology of the Philippine Trench, Pacific Ocean. Electronic Letters on Science and Engineering, 15(3), 81-94. DOI: 10.6084/m9.figshare.11449362

[63] Rona, P.A., McGregor, B.A., Betzer, P.R., Bolger, G.W., Krause, D.C., 1975. Anomalous water temperatures over Mid-Atlantic Ridge crest at $26^{\circ}$ N. Deep Sea Res. 22, 611-618. DOI: 10.1016/0011-7471(75)90048-0

[64] Petersen, S., Herzig, P.M., Hannington, M.D., 2000. Third dimension of a presently forming VMS deposit: TAG hydrothermal mound, Mid-Atlantic Ridge, $26^{\circ} \mathrm{N}$. Miner. Deposita 35, 233-259.

[65] Rona, P.A., Thompson, G., Mottl, M.J., Karson, J.A., Jenkins, W.J., Graham, D., Mallette, M., Von Damm, K., Edmond, J.M., 1984. Hydrothermal activity at the trans-atlantic geotraverse hydrothermal field, Mid-Atlantic Ridge crest at $26^{\circ}$ N. J. Geophys. Res 89, 11365-11377 